\title{
Hypermnesia and the role of imagery
}

\author{
SAMUEL J. POPKIN \\ University of Southern California, Los Angeles, California 90007 \\ and \\ MELINDA Y. SMALL \\ Bowdoin College, Brunswick, Maine 04011
}

\begin{abstract}
Subjects were instructed to produce images to either high-imagery or low-imagery word lists. Recall over three trials indicated that hypermnesia occurred in the high-imagery condition, but that a decline in performance occurred in the low-imagery condition. Furthermore, analyses of the recall of individual items indicated that the difference in recall occurred because there was less forgetting and more reminiscence in the high-imagery condition than in the lowimagery condition. The relationship between imagery and hypermnesia is discussed.
\end{abstract}

Erdelyi and Becker (1974) demonstrated that under certain conditions, memory improves with multitrial recall (hypermnesia). Their experiment compared performance on stimulus lists comprised of either pictures or words. Subjects in the word condition showed a decrease in recall over three recall trials; however, the performance of subjects in the picture condition increased over trials.

Erdelyi (Erdelyi, Finkelstein, Herrell, Miller, \& Thomas, 1977) reasoned that production of visual images promoted the hypermnesia effect. Such images would readily be produced in the picture condition, but would be less likely to occur in the word condition. This hypothesis was tested by comparing the performance of three groups. One group saw the pictures used in the Erdelyi and Becker (1974) study. The other two groups saw the verbal equivalents of the pictures. In one word condition, subjects were instructed to make images to each word as it was presented (WIM, or "words with imagery instructions"). The other word condition did not receive such instructions (WNO, or "words with no imagery instructions"). As expected, the picture condition and the WIM condition both had increased recall over trials, while the hypermnesia effect did not occur in the WNO condition.

The present experiment was designed to test the hypothesis that imagery encoding increases the likelihood of hypermnesia. In this experiment, all subjects were instructed to make images to the words. The imagery ratings of the word lists, however, were varied. Hypermnesia was expected in the high-imagery condition but not in the low-imagery group.

This research was submitted as an honors thesis for the BA degree at Bowdoin College by the first author and was supported, in part, by a Langbein Fellowship to the first author. Samuel J. Popkin is now at the Andrus Gerontology Center, University of Southern California, Los Angeles, California 90007.

\section{METHOD}

\section{Materials}

The Paivio, Yuille, and Madigan (1968) norms were used to select the two 40 -word lists. The words in the high-imagery list (Hi I) had ratings of 5 to 7; those in the low-imagery list (Lo I) were rated 1 to 3 . The frequency and meaningfulness of the words in each list were equated by selection of words with Thorndike-Lorge counts between 40 and AA and meaningfulness ratings between 4 and 6 . Two random orders of the two lists were constructed.

\section{Subjects}

The subjects were 40 undergraduates who were naive to verbal learning experiments. Twenty subjects were assigned to the Hi I list, and 20 saw the Lo I list. Within each of the conditions, half the subjects saw one random order of the word list and the others saw a second order.

\section{Procedure}

Subjects were tested in groups of one to four. They were instructed that they would see on a screen a set of words that they would be asked to recall later on. All subjects were instructed to make a visual image to each word presented.

After the stimulus presentation, recall protocols were distributed and subjects were given $7 \mathrm{~min}$ to recall, in any order, the words presented. All 40 blanks on the protocol were to be filled in within the time provided. Subjects were told to make educated guesses if necessary to complete the forced recall protocol. A 2-min and a 1-min warning were announced prior to the end of the recall period.

Protocols were then collected and put aside, with no feedback on performance given. A 7-min "think" period followed, in which subjects were instructed to "sit back and think about the items that were presented to you." A second recall trial and "think" period, and a final recall trial were then conducted.

\section{RESULTS}

An analysis of variance was performed on the number of words correctly recalled on each of the recall trials. The main effect for trials was not significant, but the main effect for imagery $[F(1,38)=51.36, p<.01]$ and the Imagery by Trials interaction $[F(2,76)=9.96$, $\mathrm{p}<.01$ ] were significant. 
As indicated in Table 1, the Hi I words were recalled better than Lo I words on all three trials. In addition, recall in the Hi I condition increased over trials and the recall of Lo I subjects declined. Follow-up analyses of variance indicated that in the Lo I condition, performance differed significantly between Trials 1 and 2 $[F(1,19)=8.88, \mathrm{p}<.01]$ and Trials 1 and $3[\mathrm{~F}(1,19)=$ $5.11, \mathrm{p}<.05$ ], but not between Trials 2 and 3 . In the Hi I condition, the difference between Trials 1 and 2 was not significant, but the Trial 2 and Trial $3[\mathrm{~F}(1,19)$ $=7.80, \mathrm{p}<.05]$ and Trials 1 and $3[\mathrm{~F}(1,19)=5.74$, $\mathrm{p}<.05$ ] differences were significant.

For Trials 2 and 3, the number of items that were recalled on Trial $n-1$, but were not recalled on Trial $n$ $(\mathrm{CN})$, and the number of items that were not recalled on Trial $n-1$ but did occur on Trial n (NC) were computed. An analysis of variance with one between-subjects variable (imagery) and two within-subjects variables (trials and change) indicated two significant effects: trials $[\mathrm{F}(1,38)=54.52, \mathrm{p}<.01]$ and Imagery by Change $[\mathrm{F}(1,38)=13.08, \mathrm{p}<.01]$.

As Table 2 illustrates, most of the change in items recalled occurred on Trial 2, and the nature of this change was very different for the two imagery conditions. Since trials did not interact with the other variables, it was collapsed in the follow-up analyses. These indicated significant differences between the imagery conditions on both the $\mathrm{CN}$ items $[\mathrm{F}(1,38)=7.87$, $\mathrm{p}<.01]$ and the NC items $[\mathrm{F}(1,38)=5.15, \mathrm{p}<.05]$.

\section{DISCUSSION}

The present results support the speculation that hypermnesia is more likely when visual imagery is used to encode the stimulus materials. When pictures are the items to be recalled, the results appear unanimous that hypermnesia is obtained (Erdelyi \& Becker, 1974; Erdelyi, Finkelstein, Herrell, Miller, \& Thomas, 1977; Hasher, Riebman, \& Wren, 1976; Madigan, 1976; Roediger \& Thorpe, 1978, Experiment 1). The effect with words, however, is less clear. Erdelyi and his colleagues do not find hypermnesia with concrete words unless specific instructions to make images are given. Others, however, find hypermnesia without special instructions (e.g., Buschke, 1973, 1974; Roediger \& Thorpe, 1978). Since it is not unusual for college students in a memory task to use imagery encoding of concrete words spontaneously, it is difficult to know the extent to which imagery does or does not contribute to the hypermnesia reported with concrete word stimuli.

A more adequate test of the role of imagery in hypermnesia would be one in which the extent of imagery encoding is under direct experimental control. The Paivio et al. (1968) norms for imagery ratings make such a manipulation possible, and as the present experiment demonstrates, hypermnesia is indeed sensitive to the extent of imagery encoding that is possible with word stimuli.

Furthermore, the analyses of the $\mathrm{CN}$ and NC components of recall demonstrate that the improved recall of the subjects in Hi I relative to the Lo I subjects occurs because forgetting (CN) is less and reminiscence (NC) is greater in the Hi I condition. These differences occur in spite of the fact that the opportunity for forgetting is greater in $\mathrm{Hi} \mathrm{I}$, since more words are recalled initially, and that the opportunity for reminiscence is less in the $\mathrm{Hi} \mathrm{I}$ condition because fewer words remain to be recalled.
Table 1

Mean Number of Correct Responses as a Function of Recall Trial and Imagery Rating

\begin{tabular}{cccc}
\hline & \multicolumn{3}{c}{ Recall Trial } \\
\cline { 2 - 4 } Imagery & 1 & 2 & 3 \\
\hline Low & 13.10 & 11.50 & 11.60 \\
High & 22.40 & 23.15 & 24.05 \\
\hline
\end{tabular}

Table 2

Mean Number of Items Forgotten (CN) and Recovered (NC)

Between Successive Recall Trials as a Function of Imagery

\begin{tabular}{cccc}
\hline \multirow{2}{*}{ Imagery } & & \multicolumn{2}{c}{ Recall Trial } \\
\cline { 3 - 4 } & & $1-2$ & $2-3$ \\
\hline \multirow{2}{*}{ Low } & $\mathrm{CN}$ & 3.15 & 1.00 \\
& $\mathrm{NC}$ & 1.50 & .60 \\
\multirow{2}{*}{ High } & $\mathrm{CN}$ & 1.90 & .35 \\
& $\mathrm{NC}$ & 2.60 & .80 \\
\hline
\end{tabular}

Recently, however, Roediger and Thorpe (1978, Experiment 2) report an experiment in which hypermnesia occurred in both low- and high-imagery conditions. Their experiment was comparable in many ways to the present one, but one difference stands out. The mean imagery rating in Roediger and Thorpe's low-imagery condition was 4.30 , which is in the middle of the possible ratings of Paivio et al. (1968) norms. Hasher et al. (1976, Experiment 2B) also report increased recall of abstract words across trials. But again, the mean ratings of these words (4.10) was in the middle of the possible ratings. In the present experiment, no word in the Lo I condition was rated above 3.

These several studies suggest, then, that the probability of hypermnesia is a function of the extent to which visual imagery is used to encode the memory items. However, Erderlyi, Buschke, and Finkelstein (1977) demonstrated hypermnesia for a list of words that was never actually presented. Rather, the memory list was generated from a series of riddles. For example, the word "bat" was generated by the subject from the riddle: "This longish wooden object is used by baseball players to hit the ball. What is it?" Forty such riddles were used to generate a memory list of 40 concrete nouns, and this list produced a greater hypermnesia effect than did a set of 40 pictures of the same items. Erdelyi, Buschke, and Finkelstein (1977) suggest that the magnitude of hypermnesia increases with greater depth of processing.

Imagery encoding, however, could occur in their riddle condition. The verbal descriptions of the riddles are very concrete and may well lead to the production of images. In fact, the images generated might well be interactive ones, involving not only the object itself (e.g., bat) but also action incorporating a ball and/or a baseball player. Thus, the Erdelyi, Buschke, and Finkelstein (1977) results do not resolve the role of imagery in hypermnesia.

Indeed, a "depth-of-processing" interpretation of hypermnesia seems premature (cf. Nelson \& Vining, 1978). Rather, future research would benefit from an emphasis on the "kinds of processing" that promote hypermnesia.

\section{REFERENCE NOTE}

1. Erdelyi. M. H. Has Ebbinghaus decayed with time? Paper presented at the annual meeting of the Psychonomic Society. Washington, D. C., November 1977. 


\section{REFERENCES}

Buschke, H. Selective reminding of memory and learning. Journal of Verbal Learning and Verbal Behavior, 1973, 12. 543-550.

BusCHKE, H. Spontaneous remembering after recall failure. Science, 1974, 184, 579-581.

ERDELYI, M. H., \& BeCKeR, J. Hypermnesia for pictures: Incremental memory for pictures but not words in multiple recall trials. Cognitive Psychology, 1974, 6, 159-171.

Erdelyi, M., Buschke, H., \& Finkelstein, S. Hypermnesia for Socratic stimuli: The growth of recall for an internally generated memory list abstracted from a series of riddles. Memory \& Cognition, 1977, 5, 283-286.

Erdelyi, M. H., Finkelstein, S., Herrell, N., Miller, B., \& Thомаs, J. Coding modality vs. input modality in hypermnesia: Is a rose a rose a rose? Cognition, 1977, 4, 311-319.
HASher, L., Riebman, B., \& Wren, F. Imagery and the retention of free-recall learning. Journal of Experimental Psychology: Human Learning and Memory. 1976, 2, 172-181.

Madigan, S. Reminiscence and item recovery in free recall. Memory \& Cognition, 1976, 4, 233-236.

Nelson, T. O., \& Vining, S. K. Effect of semantic versus structural processing on long-term retention. Journal of Experimental Psychology: Human Learning and Memory, 1978, 4, 198-209.

Paivio, A., Yuille, J. C., \& Madigan, S. Concreteness, imagery, and meaningfulness values for 925 nouns. Journal of Experimental Psychology Monograph Supplement, 1968, 76(1, Part 2).

Roediger, H. L., \& Thorpe, L. A. The role of recall time in producing hypermnesia. Memory \& Cognition, 1978, 6, 296-305.

(Received for publication March 1, 1979.) 